\title{
O PAPEL DO DESIGN GRÁFICO NO PROCESSO DE RECUPERAÇÃO DE CIDADES EUROPEIAS: ALGUNS CASOS
}

\section{THE ROLE OF GRAPHIC DESIGN IN THE REGENERATION PROCESS OF EUROPEAN CITIES. SOME CASE HISTORIES}

Emanuela F. Bonini Lessing

Emanuela Bonini Lessing, Ph.D., Assistant Professor Università Iuav di Venezia - Italy, ebonini@iuav.it)

\begin{abstract}
Graphic design draws the form of the interaction among different entities.
\end{abstract}

Citizens, administrators, institutions and local investors are specific categories of entities: they are all users (sometimes also providers) of urban services.

Graphic design is a useful tool to visually coordinate the sometimes contrasting interests of city users and stakeholders towards the use of public services and facilities.

The graphic design coordination process includes:

- focus on specific local needs (what has to be visually represented)

- highlight on addressees of the design project (communication targets): i.e. inhabitants and/or foreign investors, tourists, etc.

- design out put that, according to 
the previous steps, may include a range of products, from wayfinding system (integrating i.e. public transport, pedestrian walks, monuments' signage), to social and civic campaign encouraging some habits, like cultural integration (i.e through posters and flyers), to place branding campaign (touristic promotion abroad), etc.

As result, graphic design can contribute to reinforce and rationalize the offer of local services. This affects the way people perceive opportunities and what use they can make of public services and spaces.

Best achievements are reached when

1. Introduction - 2. the communication design process - 3. communication models and forms - 4. Conclusion - 6. References

\section{INTRODUCTION}

Graphic design shapes the relationship among entities. Citizens, administrators, institutions and investors are specific categories of entities: they are players in the urban context.

Graphic design (also called in a wider meaning visual design or communication design) can be a useful tool to coordinate the sometimes contras- the graphic design process is integrated to urban design and urban planning strategies.

A selection of case studies and best practices will be shown in the following pages.

Some Western European cities like Bristol, Amsterdam and Berlin have in the last years adopted a combination of urban design and communication design strategies. The presentation of these case histories may offer interesting methodologies in response to the need of an increment of the quality of the offer of local services and welfare. 
ting interests of the city users and stakeholders towards an increment in the quality of the use of public services and facilities. Public design and information design are the two branches of graphic design whose task is to draw the form of communication among different types of actors in a city or in a territory. On the one hand, the aim of public design is that of communicating to a large audience - possibly all city users - which services are available and how to use them (i.e. when, where, etc.). On the other hand, information design aims at giving the most suitable visual representation to the content, according to the category of users (i.e. young or elderly people, natives or foreigners), their needs (how and when getting the information), etc.

Both of them are basically two top-down communication actions: from those who decide polices and provide services to the users.

The two mentioned design branches alone are not suitable in case of a design task, whose goal is investigating the future spatial, social and economical development of a community of people. In this case public design should also include the action of showing to the local people the analysis, in forms of maps and diagrams, conducted by the designers and city developers, thanks to interviews and various forms of interactions among designers, inhabitants, local stakeholders. Rather than a vertical action, public design becomes in this case a circular communication process of listening to, showing analysis, encouraging discussions, adjusting the focus, drawing maps again and re-discussing the subject in public sessions.

At the same time, information design is the graphic tool that allow precise and comprehensible descriptions in form of diagrams and maps. It is an accurate instrument of research action more than a pure formal out-put. Information charts can show the relationship among all players acting in the selected area, focusing i.e. on the relationships between service providers and users in case of the future development of an urban area.

Public- and information design are both the scientific approach and the 
Revista da ESDM - 2016 - V. 2 - n. ${ }^{\circ} 3$

drawing tool to depict present opportunities and constraints. They make a "visioning" process possible, in which present features are the starting point for possible future development scenarios.

\section{THE COMMUNICATION DESIGN PROCESS}

The process consists of the following phases:

\subsection{FOCUS ON SPECIFIC LOCAL NEEDS}

Communication design should be involved together with other disciplines concerning the city (urban planning, architecture, urban design) at the beginning of any design process, whose goals is planning the development of a city or a territory. Thanks to their methodological analysis- based on interviews and other forms of investigation- graphic designers can draw diagrams and maps, shoot videos or other forms of visual communication highlighting the local features perceived as lacks and problems. Or, conversely, what can be considered as values and opportunities. This kind of intermediate design outputs can also help visualize citizens' expectations, hopes and claims.

For this reason communication design has to be considered as a methodological and strategic tool, not only as a "make-up" to be applied on final design out-puts;

\subsection{HIGHLIGHT ON ADDRESSEES OF THE DESIGN PROJECT: THE TARGETS}

The communication process can consist of two phases. At first, inhabitants (their thoughts, attitudes, habits) are considered as one of the primary resources. 
A "mirroring process" can be activated in which the local inhabitants can develop a first-hand understanding of what defines the area they live in. Slowly, a communication circle can be triggered among designers local residents and institutions, by collecting information and testing hypothesis.

Designers are aware that any communication project is based on a necessity that has to be clearly interpreted: i.e. do local inhabitants and stakeholders prefer to improve tourism, grow with the industrial sector or something entirely else?

In a second phase, according to the aims of the task, other addressees may be prod into acting, like foreign investors, tourists, etc..;

\subsection{DESIGN OUTPUTS}

What possible solutions are there to unlock the system providing new opportunities for initiatives that allow for one development model or another? Often such questions have no single answer. Depending on the factors previously mentioned, design out-puts may include a wide range of elements. For example social and civic campaigns, in forms of posters and flyers, encouraging some specific habits, like how to manage with garbage and municipal waste. Or place branding actions, in form of web marketing or traditional media, promoting a city to foreign tourists or investors. Or way-finding systems, integrating the information on a variety of mobility and transport services, monuments' signage, etc.

The aim of the communication design process is that of pointing out a synthesis of the main features of the territory and its uniqueness. Expectations, conflicts, cultural heritage, monuments, buildings, landmarks and present activities contribute characterizing the identity of the place.

It is important not to forget that local identity is not determined once for all. It is an on-going, multidimesional, silent, pervasive process, made by mi- 
Revista da ESDM - 2016 - V. 2 - n. ${ }^{\circ} 3$

nute every-day activities as well as by macro- changes. In design term, it is the base for the development of possible future scenarios. Thanks to this process local users and stakeholders should be able to take decisions towards an increment of the local welfare in an easier way.

\section{COMMUNICATION MODELS AND FORMS}

It is up to local administrators and institutions to decide if/how to include citizens and civic associations in this process or not. Or, conversely, it is up to citizens to demand on open and public discussion. As previously shown, the process of giving form to the communication of a city can be a vertical and hierarchical process or a participated one.

Why should the city opt for designing its own communication?

There are basically two reasons: to influence the public's opinion and perception on itself, and to control its local community's way of life.

In Europe, the relationship between local public institutions and their users mostly took place in the city itself, as was clearly expressed in the communication strategies of the London Underground railway system introduced already at the end of the 19th century. City institutions used this kind of communication to address and control citizens before the 'Internet era'. The latter were largely composed of people residing in the city who in the majority of cases were accustomed to spending almost their entire life in the same stable social and hierarchical configuration. Explicit persuasive communication strategies played limited roles in public design as strict rituals, traditions and attitudes regulated social behaviour. The preferable domain of persuasive communication lay in private and commercial fields such as advertising.

Design projects of European cities in the 20th century show a tribute to the logic of the design coordination developped by F.H.K. Henrion and A. 
Parkin (1967), and that of the information systems by T. Crosby, C. Forbes and A. Fletcher (1970), subsequently tailored to the theoretical discourse of communication on cities (Anceschi 2010).

In time European cities have lost the geographical unity which characterized them in the past (De Michelis et al 2005). Today, tension can be felt between the various centrifuge forces that tend to fragment, to break down the urban fabric into its features and ingredients, finding new ways to form clusters (Sassen 2011). A strong fragmentation becomes more apparent as information sources, communication media, message content and user types increasingly multiply.

For these reasons it is hard to believe that the hierarchical, communicational model mentioned above, which is ideally meant to produce a unitary image of the city, still corresponds to what the city today is.

\subsection{BRISTOL LEGIBLE CITY}

At present there are urban environments in which information design applied to traditional public design strategies can still coherently mirror society. In Bristol Legible City graphic design is used both as a tool for developing and visualizing the urban design process itself and at the same time for the output, consisting mainly of a way-finding system.

The urban design process itself was very long: for many years communication designers, together with urban planners and other experts of various disciplines, hold several meetings with citizens and stakeholders, in order to assure a participated action in all design phases. Graphic design was a crucial factor, making each intermediate step concerning future scenarios understandable to all participants. Only the last few years were spent to design the way-finding system, meant to allow foreigners an easier insight into Bristol most important points of interests. 
This kind of design strategy was then adopted in many other cities of Great Britain - like Sheffield, Southampton and Newcastle and others which needed a meaningful regeneration process, replacing heavy industry with new opportunities like cultural tourism and leisure.

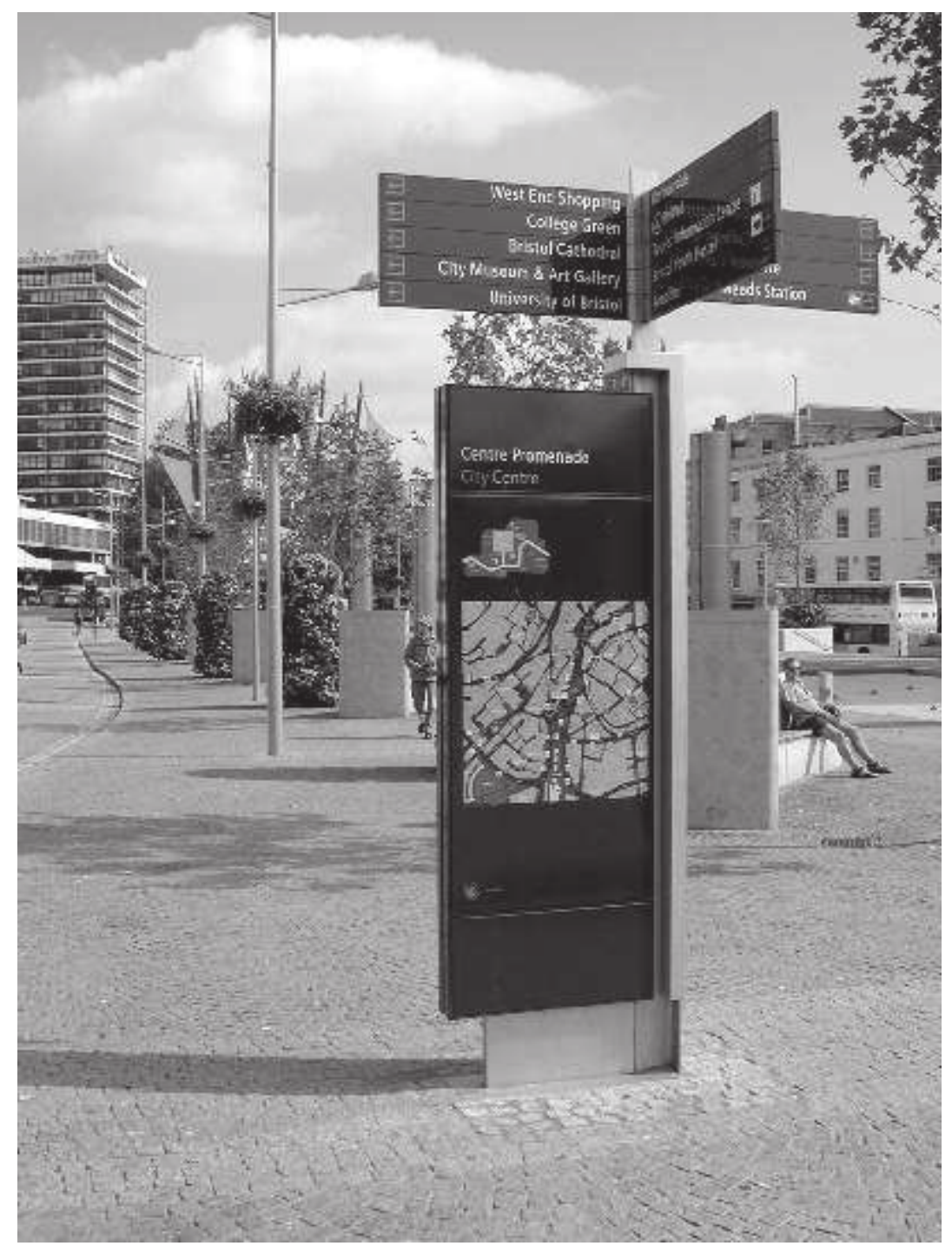

Bristol Legible City 1. One of the el ements of the urban way-finding system designed by CitylD 


\subsection{AMSTERDAM, BEBERLIN}

In cities such as Amsterdam and Berlin we can observe two different kinds of communication typologies: next to a communication based on the traditional public design model, another persuasive, seductive communication strategy linked to advertising logics is emerging. These cities have started using communication strategies that are similar to those of commercial brands and products. They try to 'absorb' within the city those who are physically excluded yet longing to become a part of, it as well as those who live inside its administrative borders but are actually 'external' or rather foreigners (for example multiethnic groups who face complicated integration processes). This gave birth to 'I Amsterdam' and 'Be Berlin' campaigns.

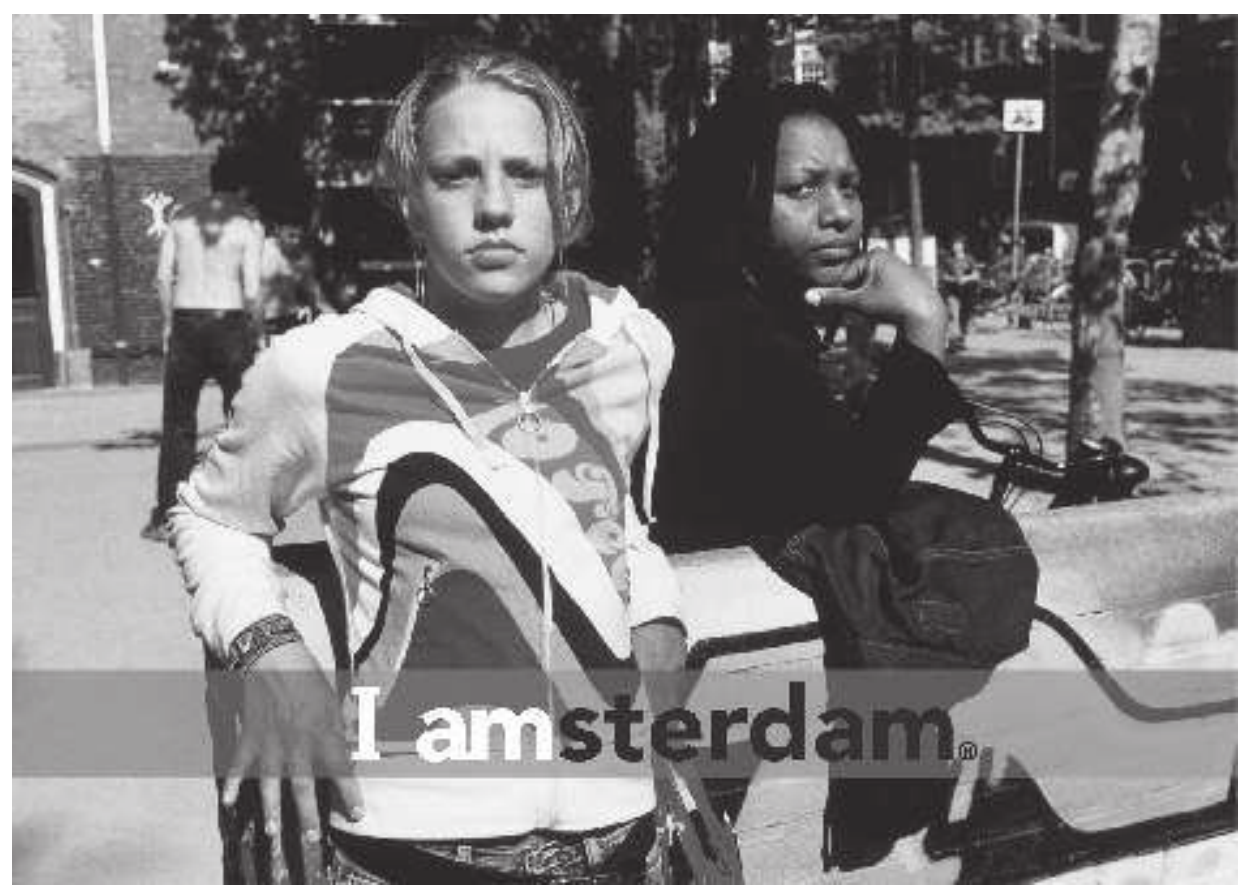

I amsterdam 1. Campaign by Kesse Ikramer, Photos may vary, the logo is printed out always in the same position 


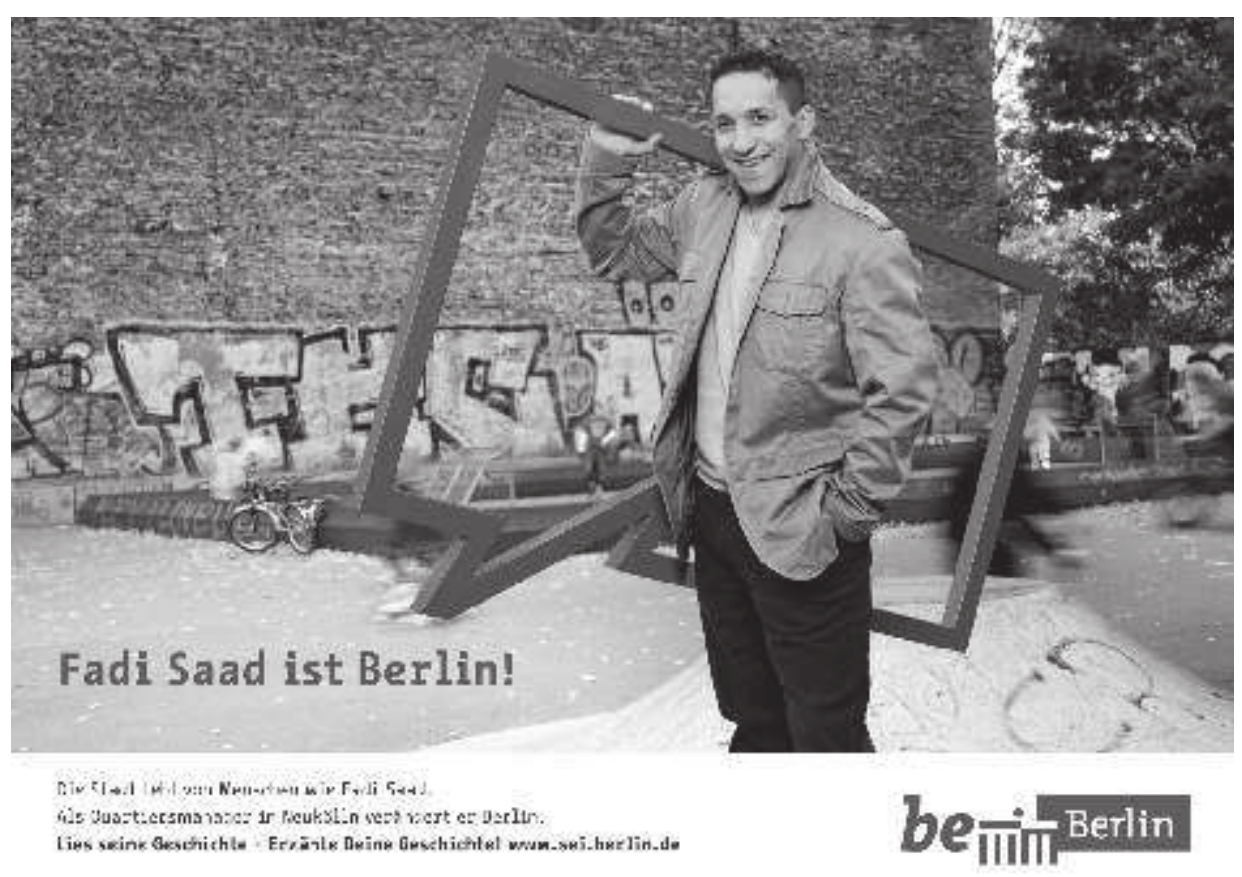

BeBer lin 1. One of the images of the communication campaign designed by Fuenfwerken, Berlin. All depicted persons carry a frame, that represents a sort of bal loon in comic strips.

The city is appealing to everyone and everyone is supposed to feel included in the city's policies. Graphic design reinforces values like multiculturalism and open-mind-attitudes that are at the base of together living in those cities, it does support changes in local economy.

Such design strategies are based on personal emotions and therefore seem to welcome and include feelings in the communication of the city to a greater extent than what traditional design models could perform or allow. Yet it still preserves a hierarchical attitude toward citizens. Within the bureaucratic machine the opportunities for citizens to express their identity, to draw and design their aspirations or frustrations are very rare. 


\subsection{WIKICITY}

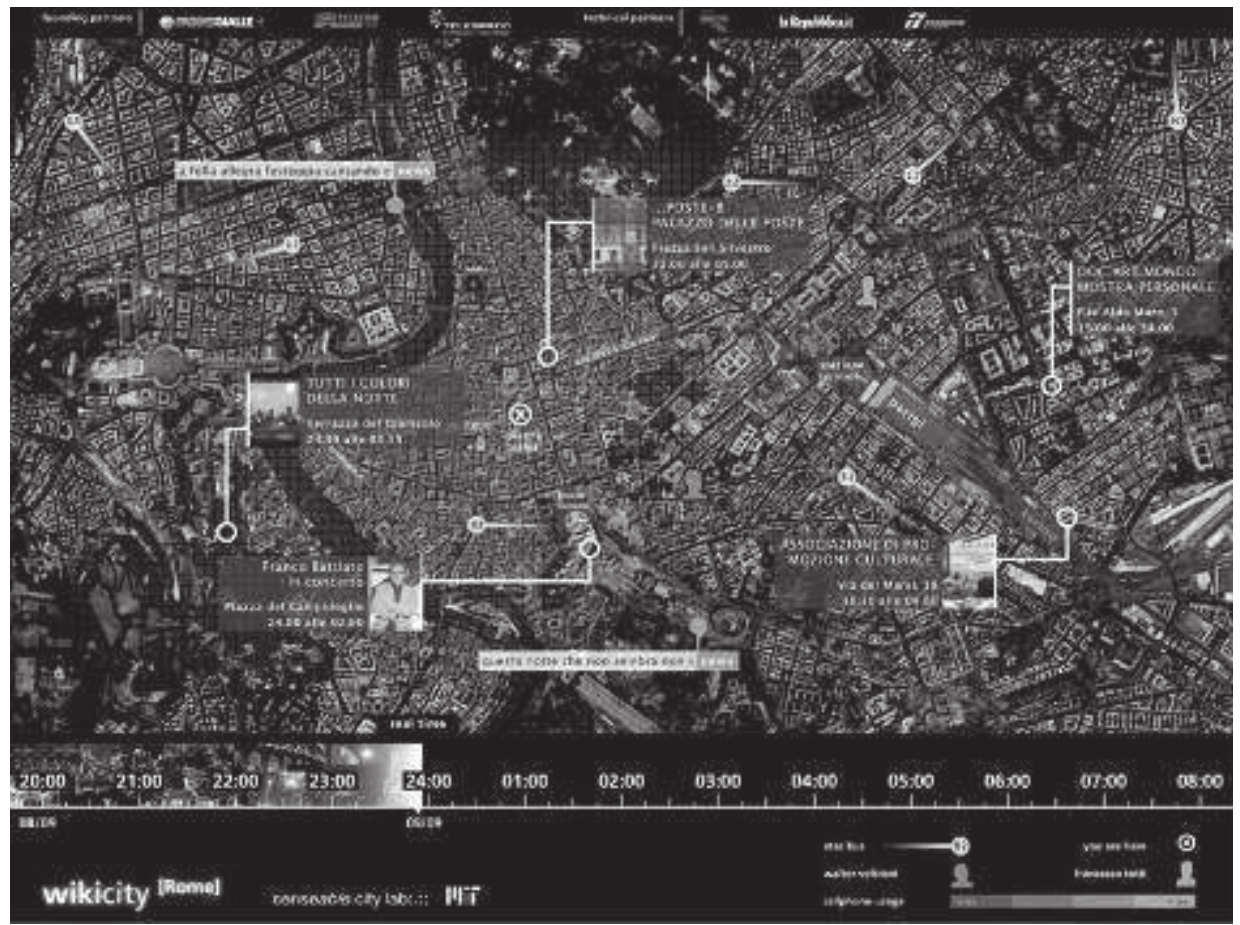

WikiCity. An interactive interface of WikiCity- Rome, 2008 by Senseable citylab, MIT

In recent years a number of experiences based on interactive design concepts have begun a new phase by introducing a gradually more participative and horizontal relationship among all stakeholders in city communication processes. This is precisely what MIT's WikiCity lab is researching: 'How can a city perform as an open source real time system?' The final representation of the city would no longer be controlled by the city administration or be a creative matter left to the designer. Most likely it would be a continuous stream of time based stratified representations of information traces drawn by the users in relation to their subjective attitudes and choices. 
Revista da ESDM - 2016 - V. 2 - n. ${ }^{\circ} 3$

This kind of bottom up communication approach seems facilitate giving voice to the different individuals and groups of citizens more democratically. It can also provide justintime reactions to the specific needs of the city users. The question is, if and how they can be turned into communication infrastructure and provider for an entire city and its citizens.

\section{CONCLUSION}

Will traditional approaches to design the image of the city possibly disappear or will there be a transformation in their aims, tools and actors in next years?

The selected case studies show that public bodies and agencies are hardly the prime movers of the process: more often temporary consortia between public and private partners are established, as an expression of local powers linked to global interests. Citizens or residents can play different roles, although rarely they are the promoters of urban regeneration programmes. Cities have proved to be voracious places where signs and images are consumed in this day and age: now more than ever cities need to manage their communication with great care. Marketing has stolen space traditionally taken up by public use and social communication acting alongside the progressive privatization of society in in many European countries (Olins 2002, Wolf 1999).

Tension can be felt between the various centrifuge forces which tend to fragment, to break down the urban fabric into its features and ingredients, finding new ways to form clusters. Visual communication can thus easily feed on the repertoire of classical principles of information design, reconsidering the aims of public design and not disdaining the advertising register.

Furthermore, as some European sociologist and urban planners (Amendola, Indovina and Latour) have observed from different points of view, con- 
temporary city tend to escape a comprehensive view. Traditional communication models finds it difficult to incorporate the point of view of those who experience urban living 'from below', unlike digital and interactive technologies, that seem to make it possible. Neither truths nor stable representations in time seem necessary with them. In this sense, WikiCity projects investigate their limits and at the limit of data presentation modes in a relentless transfiguration, shifting forward the threshold of information and public design.

In this context, the discipline of graphic design emerges fragmented by the changes of this century. Broken, but like the city itself, in the fragments it represents, it is ready to reorganize itself in original and occasional forms.

Will public administrations understand the necessity of reshaping current decision making processes and welcome authentic participative practices? Will it be possible to face the task of urban communication as a playful, changeable mosaic, network or bundle of multiple opportunities?

\section{REFERENCES}

AMENDOLA, Giandomenico: La città postmoderna. Magie e paure della metropoli postmoderna, Laterza, Roma- Bari, 1997.

ANCESCHI, Giovanni: L'interfaccia delle città. In Bonini Lessing E. F.: Interfacce metropolitane. Frammenti di corporate identity, Et Al, Milano, 2010.

BONINI LESSING, EMANUELA F.: Interfacce metropolitane. Frammenti di corporate identity, Et Al, Milano, 2010

BONINI LESSING, EMANUELA F. (eds): Delta Landscape 2100, Professionaldreamers, Trento, 2012

BONINI LESSING, EMANUELA F. (eds): Urban safety and security, Franco Angeli, Milano, 2015

CHAPELLE José, EVENO Claude: L'image d'utilité publique, Centre Pompidou, Paris, 1988.

CROSBY, Theo et al: A sign System manual. Praeger Pub., London, 1970.

DE MICHELIS, Marco et al (eds.): M Stadt. Europaeische Stadtlanschaften/M City. European citiscape, Walter Koening, Koeln, 2005. 
Revista da ESDM - 2016 - V. 2-n. 3

HENRION, Fredrick H.K., PARKIN, Alan: Design coordination and corporate image, Studio Vista, London, 1967.

INDOVINA, Francesco: Organizzazione dello spazio e processi di socializzazione nei nuovi territori dell'arcipelago metropolitano. In: MARRONE, Gianfranco, PEZZINI, Isabella, Senso e Metropoli. Per una semiotica posturbana, Meltemi, Roma, 2006

LATOUR, Bruno: Paris, ville invisible, in http//www.bruno-latour.fr

OLINS, Wally: Branding the nation. The historical context. In: "The journal of brand management", Vol 9, 2002.

SASSEN, Saskia: Cities in a world economy, Pine Forge Pres, 2011.

WOLF, Michael J.: The Entertainment Economy, Random House, New York, 1999. 